\title{
The Use of Landsat and Aerial Photography for the Assessment of Coastal Erosion and Erosion Susceptibility in False Bay, South Africa
}

\author{
Kerry Callaghan ${ }^{1}$, Jeanine Engelbrecht ${ }^{2}$, Jaco Kemp ${ }^{1}$ \\ ${ }^{1}$ Department of Geography and Environmental Sciences, Stellenbosch University, Stellenbosch, \\ South Africa, kerrylee37@gmail.com \\ ${ }^{2}$ CSIR Meraka Institute, Stellenbosch, South Africa
}

DOI: http://dx.doi.org/10.4314/sajg.v4i2.1

\begin{abstract}
Coastal erosion is a worldwide hazard, the consequences of which can only be mitigated via thorough and efficient monitoring of erosion. This study aimed to employ remote sensing techniques on aerial photographs and Landsat TM/ETM+ imagery for the detection and monitoring of coastal erosion in False Bay, South Africa. Vegetation change detection as well as post-classification change detection were performed on the Landsat imagery. Furthermore, aerial photographs were analysed using the Digital Shoreline Analysis System (DSAS), which determines statistical differences in shoreline position over time. The results showed that while the resolution of the Landsat imagery was not sufficient to quantify and analyse erosion along the beach itself, the larger area covered by the satellite images enabled the identification of changes in landcover conditions leading to an increased susceptibility to erosion. Notably, the post-classification change detection indicated consistent increases in built-up areas, while sand dune, beach, and sand (not beach) decreased. NDVI differencing led to the conclusion that vegetation health was decreasing while reflective surfaces such as bare sand and roads were increasing. Both of these are indicative of an increased susceptibility to coastal erosion. Aerial photographs were used for detailed analysis of four focus areas and results indicated that coastal erosion was taking place at all four areas. The higher resolution available on the aerial photographs was vital for the quantification of erosion and sedimentation rates.
\end{abstract}

\section{Introduction}

Coastal erosion is a worldwide hazard, often resulting in damage to roads and other infrastructure. Natural forces such as wind, waves and currents cause reshaping of coastlines (Phillips, 2008; Unterner et al., 2011), while anthropogenic effects are also associated with coastline degradation (Siripong, 2010; Smith and Abdel-Kader, 1988; Unterner et al., 2011). Monitoring and 
assessment of coastal erosion facilitates planning to protect infrastructure and the coastal environment. Remote sensing investigations of hazards in general and coastal erosion in particular, can lead to conclusions which may aid in disaster management and the formulation of relief strategies (Tralli et al., 2005).

Various aspects of coastal erosion have been assessed in previous investigations. These included the creation of coastal vulnerability indices (e.g. Boruff et al., 2005; Palmer et al., 2011; Unterner et al., 2011; Zhang et al., 2011); investigation of erosion criteria using remotely sensed imagery (e.g. Huang and Fu, 2002; Siripong, 2010); statistical analysis of rates of change and other factors (e.g. Thampanya et al., 2006); and the creation of numerical models for erosion (e.g. Hanson, 1988). Past studies on the susceptibility of the South African coastline to coastal erosion (Palmer et al., 2011; Unterner et al., 2011) have focused on the creation of an index of erosion susceptibility for the coastline based on factors such as beach width and wave height, but have not incorporated change detection to determine where erosion and changes to erosion susceptibility are occurring.

This study aimed to employ both high- and medium resolution remote sensing datasets and a selection of image processing techniques for the detection and monitoring of long-term coastal erosion in the False Bay region (Figure 1). Based on the assessment, recommendations for data sources and processing techniques for future assessments of coastal erosion and susceptibility to erosion within South Africa or other regions can be made. The False Bay area comprises different beach types, including cliffs and sandy beaches. Four areas of interest for detailed analysis of erosion rates, as highlighted in Figure 1, have been identified. The beaches, including Bayview Heights, Macassar Beach, Strand, and Pringle Bay, were selected due to their high coastal erosion susceptibility (Unterner et al., 2011).

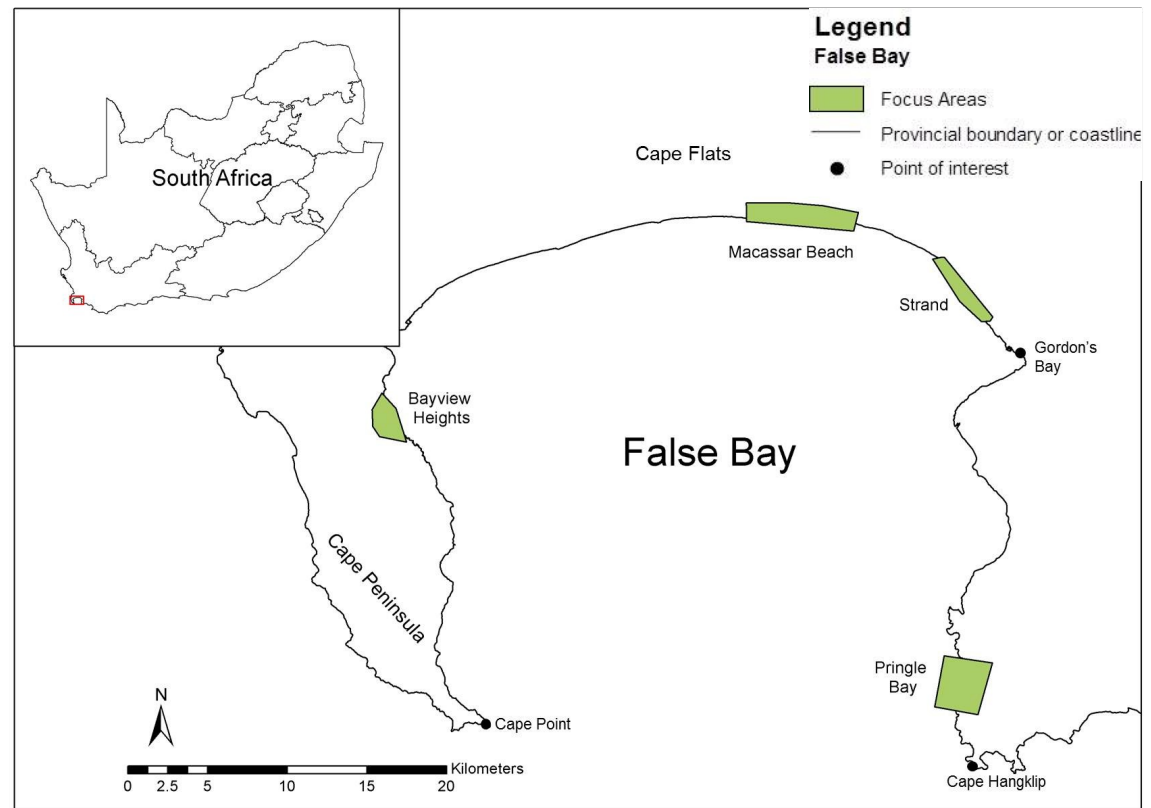

Figure 1. The study area: False Bay, South Africa. The green polygons indicate focus areas investigated using aerial photographs. 


\section{Methods}

This study aimed to employ a selection of remote sensing image analysis techniques for change detection in beach and coastal zones with the aim of assessing coastal erosion and the susceptibility to erosion over time. The use of remotely sensed data enables repetitive data acquisition, which is vital for the detection of land cover changes over time (Mouat et al., 1993). Both aerial photographs and Landsat TM imagery have been used in numerous change detection investigations (e.g. Althausen et al., 2003; Hayes and Sader, 2001; Kwarteng and Al-Ajmi, 1996; Smith and AbdelKader, 1988; Thampanya et al., 2006; van der Werff and van der Meer, 2008; Zhang et al., 2002, and others). This investigation employed Landsat image classification and post-classification change detection to identify changes that may affect the region's susceptibility to erosion. Furthermore, the change in normalised difference vegetation indices (NDVI) were used to identify areas where a decrease in the health and productivity of vegetation may lead to increased susceptibility to erosion.

In addition to identifying changes in surface conditions affecting the susceptibility to erosion, digital shoreline analysis was performed on high resolution aerial photography in an attempt to quantify erosion and sedimentation rates in the four focus areas identified in Section 1. The image classification and change detection as well as the digital shoreline analysis is discussed in more detail in section 2.1 and 2.2 respectively.

\subsection{Classification and change detection using Landsat data}

The classification and change detection of a time series of Landsat data was performed in an effort to identify particular changes in land cover conditions that may lead to increased erosion susceptibility. For this purpose, six Landsat images, captured during the same seasonal period between 1985 and 2011 (Table 1) were obtained, along with a DEM (SUDEM - Stellenbosch University Digital Elevation Model (Van Niekerk, 2012)). Atmospheric correction and radiometric calibration were performed using ATCOR 2 to convert digital numbers to surface reflectance.

Table 1. The Landsat images used. The Path/Row number for all acquisitions was 175/84.

\begin{tabular}{|l|l||l|l|}
\hline Acquisition Date & Satellite & Acquisition Date & Satellite \\
\hline $1985 / 05 / 11$ & Landsat 5 TM & $2001 / 05 / 15$ & Landsat 7 ETM+ \\
\hline $1991 / 05 / 28$ & Landsat 5 TM & $2006 / 04 / 19$ & Landsat 5 TM \\
\hline $1996 / 05 / 25$ & Landsat 5 TM & $2011 / 04 / 17$ & Landsat 5 TM \\
\hline
\end{tabular}

Object-based image classification was performed to identify 11 land cover classes of interest. These include 1) beach, 2) built-up, 3) cultivated, 4) dams, 5) mountain, 6) mountain shadow, 7) natural, 8) ocean, 9) sand (not beach), 10) sand dunes and 11) shallow coastal. The object-based image classification was selected since various studies have found them more accurate than pixelbased methods (Drăguț et al., 2010; Kamagata et al., 2006; Ryherd and Woodcock, 1996; Sun et al., 2004) and has been found useful for landcover studies using Landsat (Lyons et al., 2012). The 
classification was achieved using a segmentation scale of 18 as determined by the ESP tool (Drăgut et al., 2010). The shape and compactness values were both set to 0.3. Due to its simplicity and computational efficiency, a supervised neural network (NN) classification was performed. Samples were collected from the images themselves as well as from high resolution aerial photographs, and were randomly separated into training and reference samples. The reference samples were used for post-classification accuracy assessment and not included in the classification training samples.

Following image classification, post classification change detection was performed to assess changes in the coastal zone that may affect the susceptibility to coastal erosion over time. To simplify the visualisation of the post classification change detection results, the 11 classes identified in the image classification stage were reduced to 4 classes to highlight only the changes that affect the susceptibility to erosion. The beach, built-up and sand dune classes were retained as classified while cultivated, dams, mountain, mountain shadow, natural, ocean, sand (not beach) and shallow coastal classes were merged.

In addition to post classification change detection, NDVI (Normalised Difference Vegetation Index) differencing was performed to observe the changes in vegetation over time as a potential indicator of a change in erosion susceptibility. This has a direct application to erosion and erosivity since a decreased NDVI shows decreases in vegetation health and density, which increases susceptibility to erosion (Kwarteng and Al-Ajmi, 1996; Thampanya et al., 2006). NDVI change analysis was performed by segmenting the NDVI data according to its value in steps of 0.1 . The segmented scenes were compared to highlight the changes in vegetation productivity between 1985 and 2011. The results of the post-classification change detection and NDVI change assessment is presented in Sections 3.1 and 3.2 respectively.

\subsection{Shoreline change detection using aerial photographs}

To also assess smaller scale changes in coastal areas over longer periods, aerial photographs captured at various dates between 1944 and 2010 were used (Table 2). The Digital Shoreline Analysis System (DSAS) developed by Thieler et al. (2009) was used to assess beach positional changes. The DSAS tool provides the ability to calculate various rate-of-change statistics from a time series of vector data (Thieler et al., 2009). The rate-of-change statistics reported on in this investigation include the net shoreline change as well as the least median of squares indicator (LMS), which measures the change in the shoreline position as a rate of change in metres per annum. Negative LMS values are indicative of erosion over time whereas positive values are indicative of accretion over time.

The four focus areas, Bayview Heights, Macassar Beach, Strand, and Pringle Bay (Figure 1) were selected for more detailed analysis using aerial photography. Shoreline positions were manually digitised from the photographs at the different dates of image acquisition for each focus 
area. The wet/dry line was used as a shoreline indicator. This is the distinct visible edge between the wet and dry portions of the beach (Boak and Turner, 2005).

Table 2. Details of the aerial photographs utilised.

\begin{tabular}{|l|l||l|l|}
\hline Date & Areas Covered & Date & Areas Covered \\
\hline 2010 & All & $27-09-1977$ & Strand \\
\hline $03-2009$ & Bayview; Macassar; Strand & $27-03-1977$ & Macassar; Strand; Pringle Bay \\
\hline 2008 & Bayview; Macassar; Strand & $23-04-1976$ & Bayview \\
\hline $09-11-2000$ & All & $12-05-1971$ & Macassar; Strand \\
\hline $07-06-1999$ & Macassar; Strand & $21-10-1968$ & Bayview \\
\hline $09-09-1989$ & Bayview; Pringle Bay & $01-04-1968$ & Macassar \\
\hline $28-07-1989$ & Macassar; Strand & $26-01-1967$ & Macassar \\
\hline $27-05-1989$ & Bayview & $10-12-1966$ & Strand \\
\hline $26-01-1989$ & Bayview & $31-10-1961$ & Pringle Bay \\
\hline $25-08-1988$ & Strand; Pringle Bay & $10-1958$ & Bayview \\
\hline $17-04-1983$ & Macassar & $11-1953$ & Strand \\
\hline $09-03-1980$ & Pringle Bay & 1945 & Bayview \\
\hline $27-04-1978$ & Strand & 1944 & Bayview; Macassar; Strand \\
\hline $04-10-1977$ & Bayview & & \\
\hline
\end{tabular}

\section{Results}

\subsection{Classification and Change Detection Results}

The result of the object-based classification on the Landsat scene captured on 2011/04/17 is presented in Figure 2. Accuracy assessment on the classified scenes showed high overall accuracies of over $85 \%$ and kappa values over 0.8 for all six scenes. However, the individual class accuracies were more variable with over $99 \%$ accuracy for the ocean class but $65.9 \%$ accuracy for the sand dunes class. The producer's accuracy for the sand dunes was high $(80 \%)$ while lower values were seen in the user's accuracy due mostly to sand dunes being misclassified as natural. These two classes were visually similar so portions near the beach which have been classified as natural were likely actually sand dunes.

Post-classification change detection was achieved using the 1985/05/11 and 2011/04/17 classifications as input, effectively highlighting the changes in surface conditions between these dates. The percentage increase or decrease in each of the classes is presented in Table 3 . The result of the post classification change detection is presented in Figure 3. 


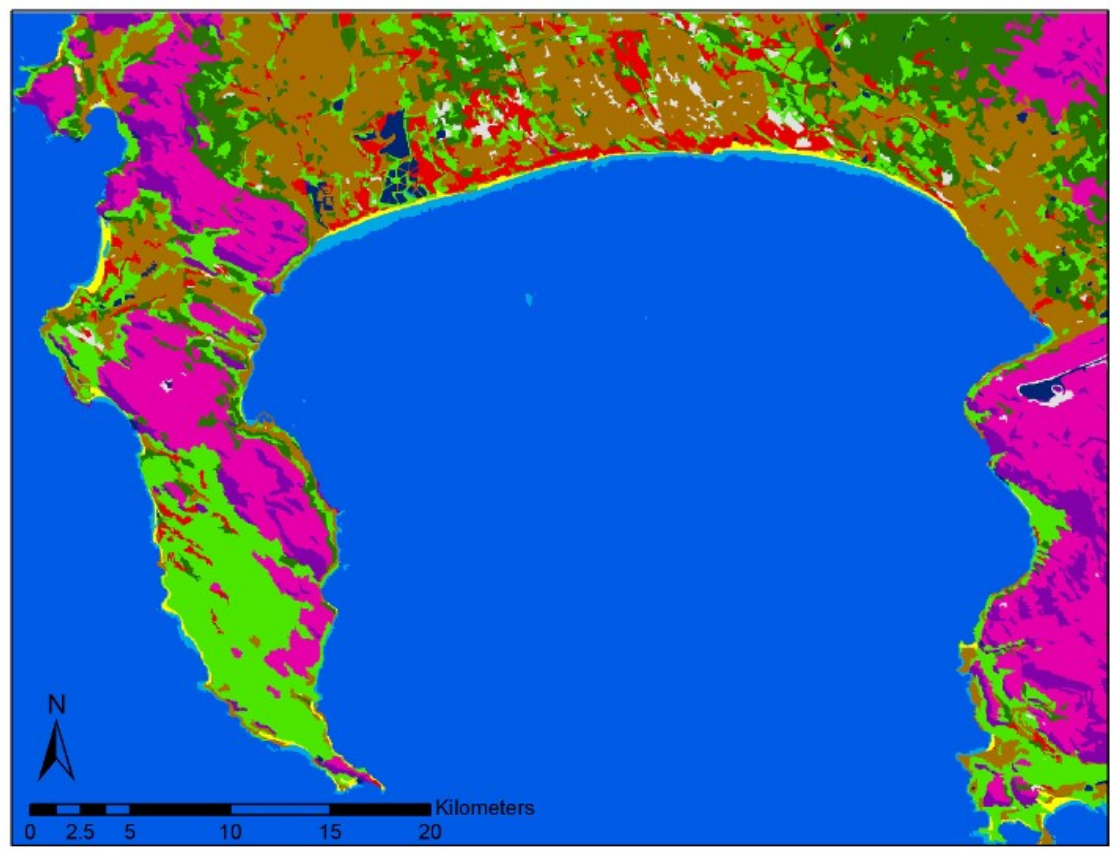

\section{Legend}

Object-based classification

Class_name

Beach

Built-up

Cultivated

Dams

Mountain

Mountain shadow

Natural

Ocean

Sand (not beach)

Sand Dune

Shallow coastal

Figure 2. The object-based classification on the 2011/04/17 Landsat TM image.

The most significant changes were seen in the built-up class which rapidly expanded between the dates of image acquisition. This was an indicator of increased risk of beach and dune erosion, since urban expansion often comes at the cost of natural vegetation. There is a corresponding steady decrease in the sand dune class. Increases in the shallow coastal class may be the result of a buildup of sand off the beach, although other causes including changing tidal levels or increased phytoplankton are also possible. The beach class indicated a net decrease although this appears to fluctuate over time. The fluctuation may be the result of varying tidal conditions at the time of image acquisition. However, the large pixel size $(30 \mathrm{~m})$ means that a change of even a single pixel could be indicative of considerable erosion. The resolution of the Landsat imagery was not sufficient to definitively detect changes in beach position.

Table 3. The changes in area of each class shown as a percentage of that specific class. The bottom row shows the total percentage change per class from 1985 to 2011.

\begin{tabular}{|l|l|l|l|l|l|l|l|l|l|l|}
\hline & Beach & $\begin{array}{l}\text { Built- } \\
\text { up }\end{array}$ & Cultivated & Dams & Mountain & Natural & Ocean & $\begin{array}{l}\text { Sand (not } \\
\text { beach) }\end{array}$ & $\begin{array}{l}\text { Sand } \\
\text { dune }\end{array}$ & $\begin{array}{l}\text { Shallow } \\
\text { coastal }\end{array}$ \\
\hline $\mathbf{1 9 8 5}$ & 0.00 & 0.00 & 0.00 & 0.00 & 0.00 & 0.00 & 0.00 & 0.00 & 0.00 & 0.00 \\
\hline $\mathbf{1 9 9 1}$ & -23.35 & 9.02 & 35.07 & -6.78 & 1.64 & -31.05 & -0.18 & -13.09 & -14.12 & -1.51 \\
\hline $\mathbf{1 9 9 6}$ & -12.13 & 7.64 & -14.69 & 22.45 & -3.10 & 3.25 & 0.29 & -9.97 & 32.21 & -11.36 \\
\hline $\mathbf{2 0 0 1}$ & 31.48 & 19.42 & -25.47 & -11.24 & -0.04 & 8.94 & -0.48 & -5.52 & -5.01 & 89.63 \\
\hline $\mathbf{2 0 0 6}$ & -11.74 & -4.72 & 37.16 & -8.76 & -6.50 & -1.60 & 0.13 & 9.22 & -20.37 & -17.29 \\
\hline $\mathbf{2 0 1 1}$ & 20.03 & 5.20 & -28.72 & 1.49 & 9.71 & 25.83 & -0.57 & -5.01 & -25.56 & 27.02 \\
\hline Total & -6.17 & 40.46 & -16.04 & -6.19 & 0.99 & -3.99 & -0.81 & -23.31 & -36.06 & 73.93 \\
\hline
\end{tabular}




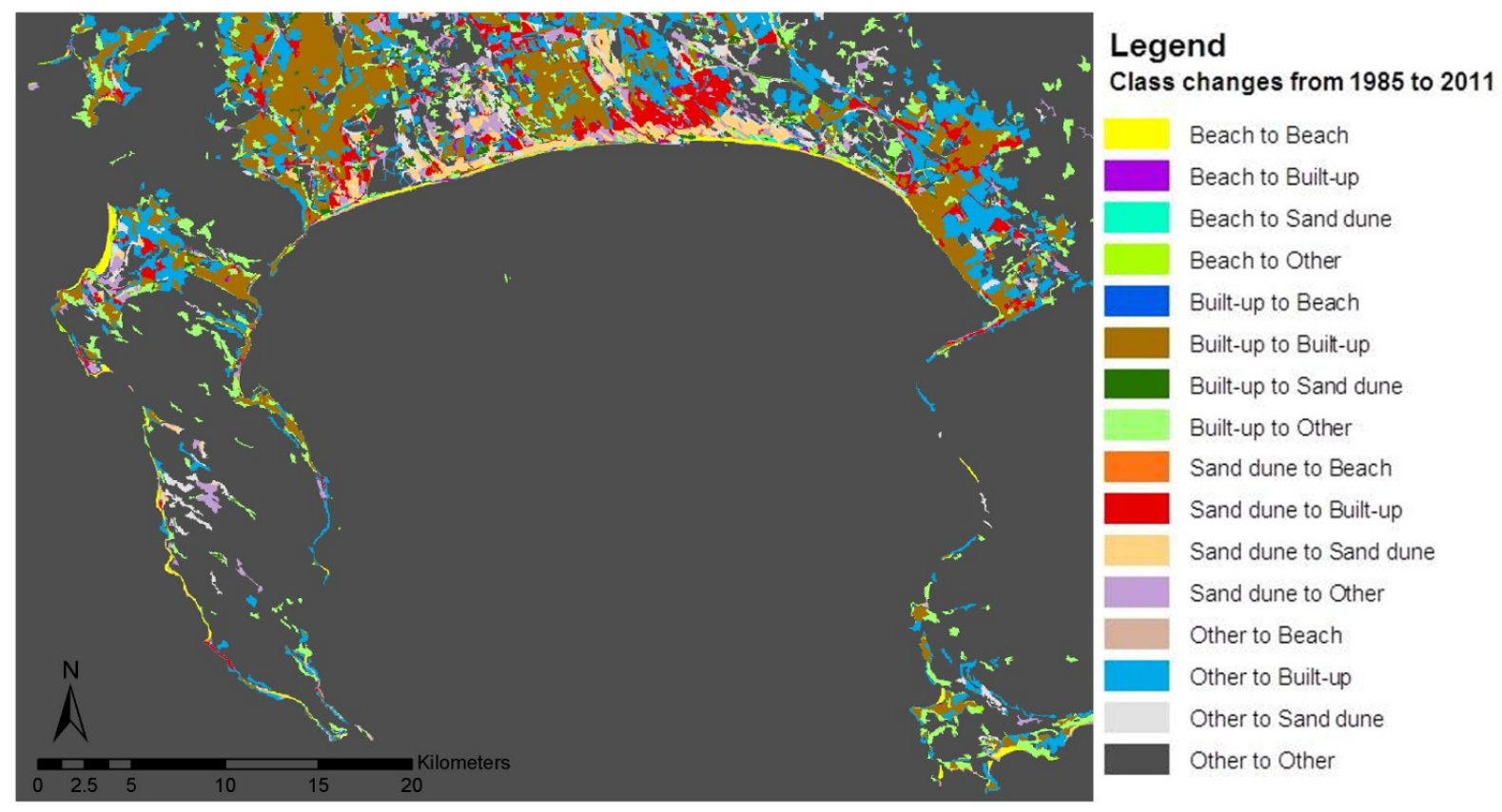

Figure 3. Changes between beach, dunes, built-up, and other classes from 1985 to 2011. Note the extensive red and cyan areas indicating expansion of the built-up class.

\subsection{Changes in NDVI}

The analysis of the change in NDVI as an indicator of change in the health and productivity of vegetation was performed by considering the 1985 and 2011 NDVI results. The results reveal that the majority of the area of interest exhibited a decrease in vegetation health and productivity with decreases in NDVI values between 0.1 and 0.8 recorded. A visual assessment showed that the NDVI was highest in 1985 and lowest in 2011. Most periods showed a decrease in NDVI with drastic decreases when assessing the NDVI over the whole study period (Figure 4). Decreases in vegetation density and health naturally results in increased susceptibility to erosion within the study area. Considerable urbanisation within the study region has resulted in removal of some vegetation, while vegetation health may have decreased in other areas. These changes correspond to the observations made in post-classification change detection since an overall increase in built-up areas and a decrease in natural vegetation and cultivated areas were observed. This further confirms that a reduction in vegetation and an increase in artificial reflective surfaces may affect the susceptibility to coastal erosion in the area. 


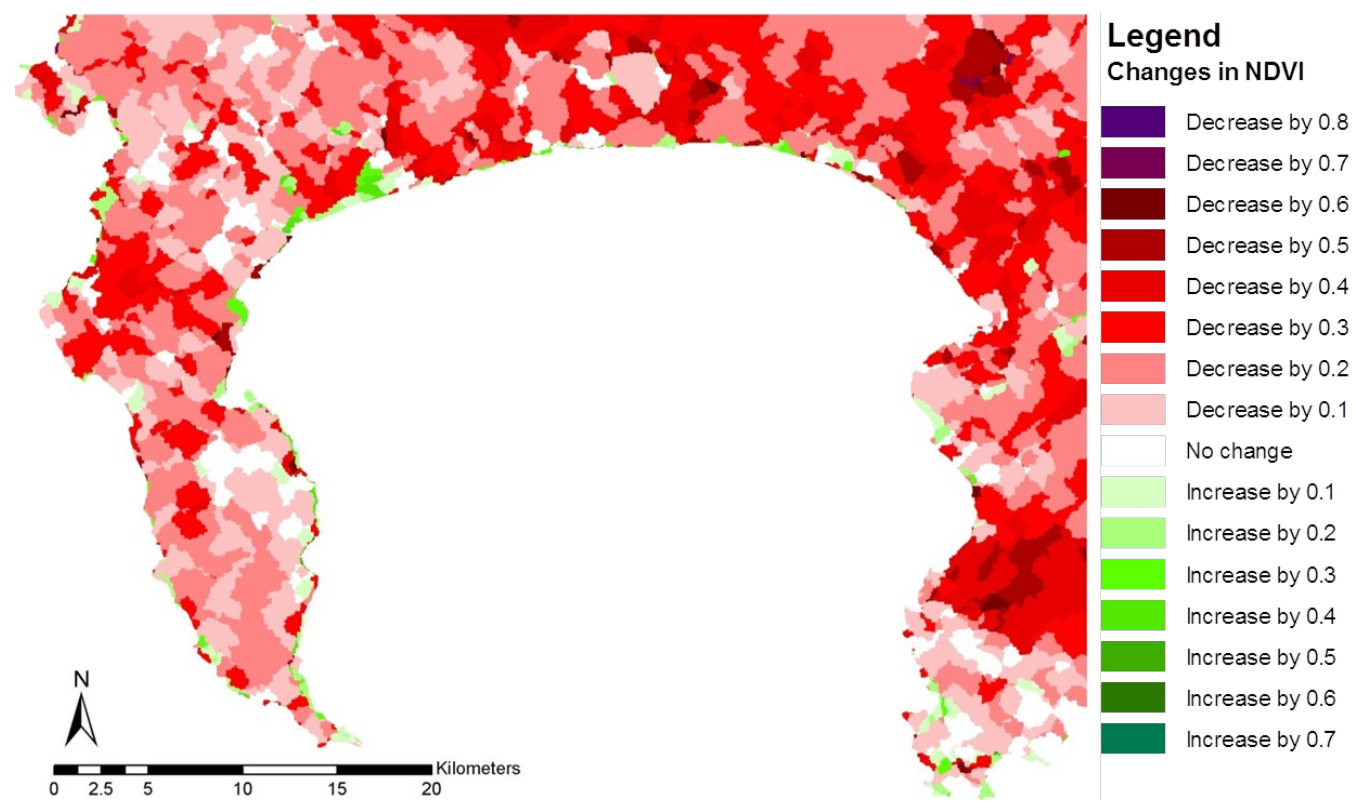

Figure 4. Changes in NDVI over the entire study period, from 1985 to 2011 . The extensive red areas indicate decreases in NDVI throughout the study region.

\subsection{Shoreline Change Analysis Results}

The Digital Shoreline Analysis System (DSAS) was designed specifically for use in analysing shoreline change (Thieler et al., 2009). In this study, it was used on aerial photographs to provide information on erosion trends in the four focus areas. In Figure 5 to Figure 8 in Sections 3.3.1 to 3.3.4, the lengths of the lines represent gross positional change in shoreline position over the study period. While the rates of change per year are often smaller than the pixel sizes of the images used, the overall change being observed over 66 years in these focus areas is larger than the pixel sizes and therefore the general trends can be observed.

\subsubsection{Bayview Heights}

In Bayview Heights, the net shoreline change from 1944 to 2010 ranged from $26.10 \mathrm{~m}$ erosion in some places to $45.47 \mathrm{~m}$ accretion in others. In this region, cyclical changes between erosion and accretion were observed. The least median of squares indicator (LMS), (Figure 5) ranged from 1.38 $\mathrm{m}$ erosion to $0.70 \mathrm{~m}$ accretion per year with an average of $0.17 \mathrm{~m}$ erosion per year.

Although a past study identified this as a region with high erosion susceptibility (Unterner et al., 2011), it showed the smallest rate of change indicators of the four focus areas. However, the area is very dynamic with fluctuations between erosion and accretion over time. Net erosion was observed for the area towards the northern edge of the focus area while the southern region experienced net accretion. 


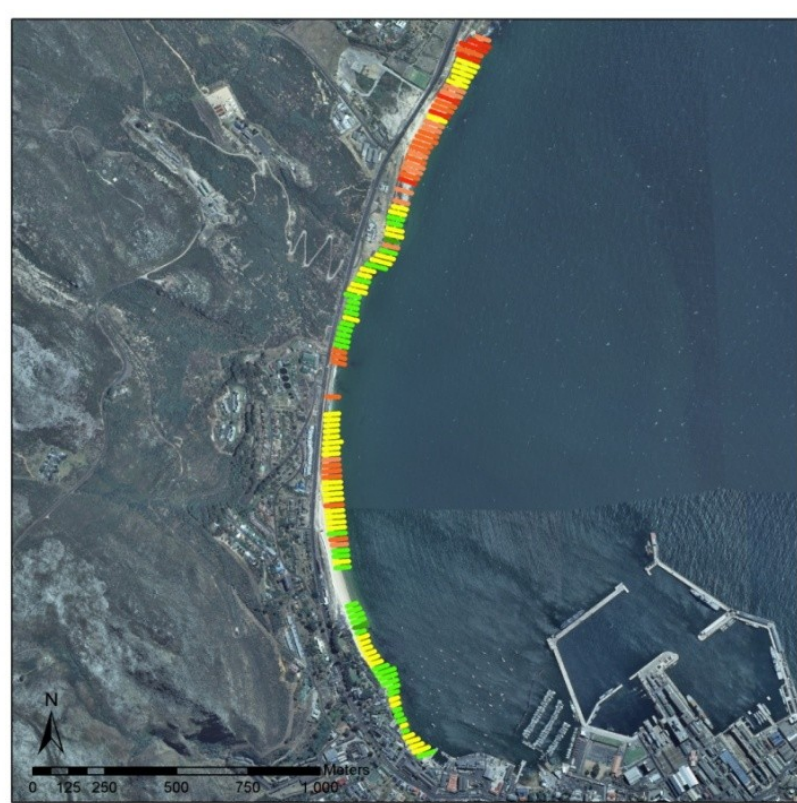

\section{Legend}

Beach changes at Bayview Heights

Least Median of Squares

$-1.38--0.87$

$-0.86--0.44$

$-0.43--0.20$

$-0.19-0.00$

$0.01-0.27$

$0.28-0.70$

Figure 5. Least median of squares in metres per year at Bayview Heights.

\subsubsection{Macassar Beach}

Drastic changes in shoreline position were observed at the Macassar Beach focus area. The net shoreline movement ranged from 73.49 m erosion to $90.47 \mathrm{~m}$ accretion from 1944 to 2010, with an average of $7.13 \mathrm{~m}$ erosion. The construction of a tidal pool towards the western end of the study area resulted in an artificial increase in the detected accretion. Actual accretion did occur towards the eastern end of the study region. The LMS (Figure 6) ranged between $1.38 \mathrm{~m}$ erosion per year and $5.19 \mathrm{~m}$ accretion per year with an average of $0.14 \mathrm{~m}$ erosion per year.

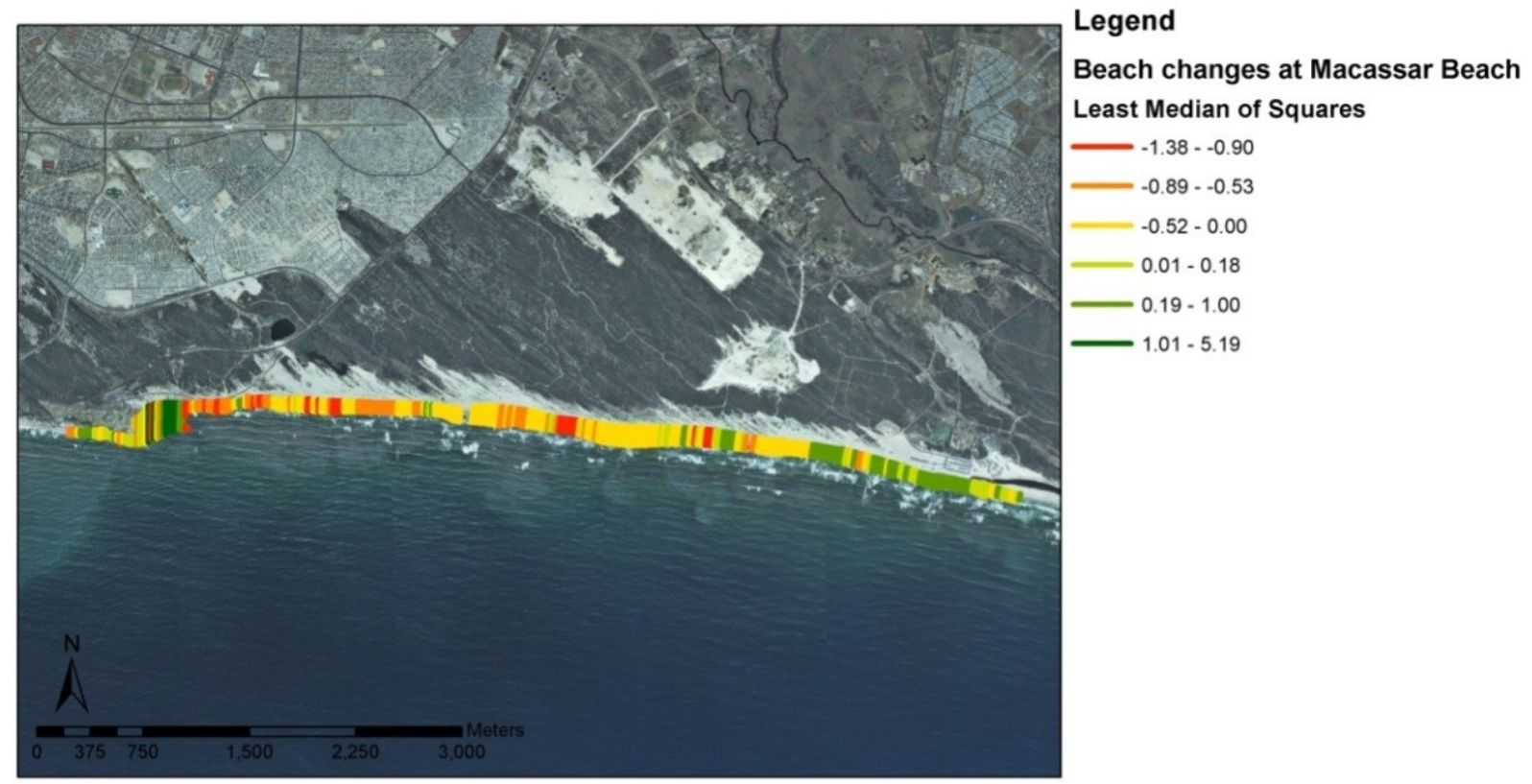

Figure 6. Least median of squares at Macassar Beach. 


\subsubsection{Strand}

Strand was the only one of the four focus regions which showed no net accretion between 1944 and 2010. The net shoreline movement ranged from $0.06 \mathrm{~m}$ to $122.43 \mathrm{~m}$ erosion, with an average of $39.099 \mathrm{~m}$ erosion. However, the LMS (Figure 7) ranged from $2.37 \mathrm{~m}$ erosion to $1.97 \mathrm{~m}$ accretion per year, with an average of $0.50 \mathrm{~m}$ erosion per year. The net accretion rate as identified by LMS indicates that, although net shoreline movement indicated only erosion, some cyclical accretion did take place. This means that the LMS statistic, which uses all the dates, provides data not only about the overall changes, but also about cyclical changes and variations which are often invisible when assessing only two dates.

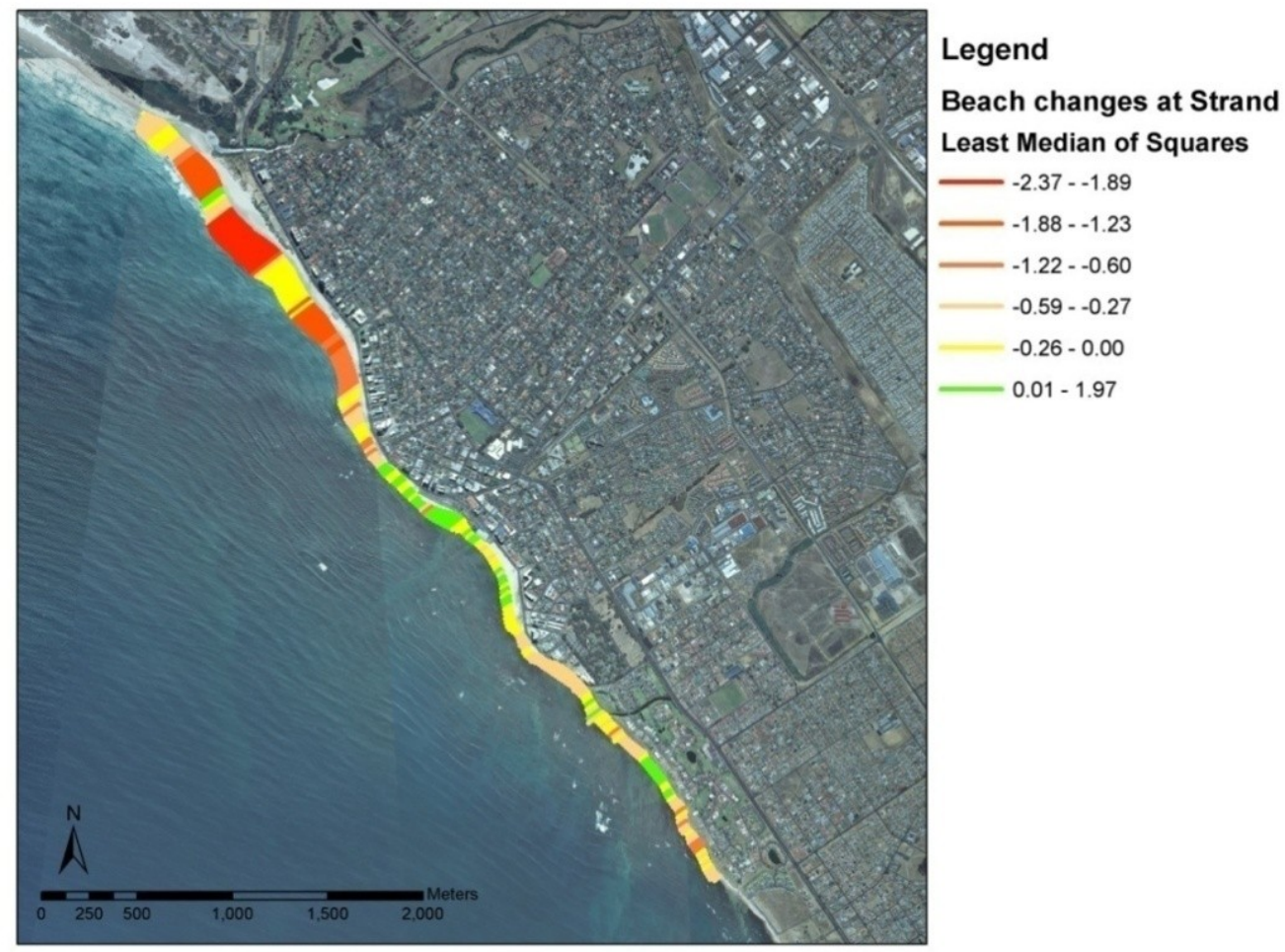

Figure 7. Least median of squares at Strand. The average LMS indicates $0.50 \mathrm{~m}$ of erosion has been occurring per year.

The fact that only net erosion is occurring in this focus area could have serious implications for structures in this region in coming years. The Beach Road at Strand is next to the beach and at times, mere metres from the ocean. The most erosion in this focus area occurred in the northwestern parts of the study area, gradually decreasing to the south-east. This could be an indication of a longshore current eroding more material from the north-western regions. The beach was also broadest in the north-western region, supplying more material for erosion. Increases in built-up zones in this focus area are also indicative of an increased susceptibility to erosion. 


\subsubsection{Pringle Bay}

The net shoreline movement at Pringle Bay ranged from $128.63 \mathrm{~m}$ erosion to $19.27 \mathrm{~m}$ accretion, averaging $65.20 \mathrm{~m}$ erosion. Since not all of the aerial photographs covered this region, the temporal range was from 1961 to 2010. The LMS (Figure 8) ranged from $3.25 \mathrm{~m}$ erosion per year to $0.32 \mathrm{~m}$ accretion per year with an average of $1.46 \mathrm{~m}$ erosion per year. The erosion in this area was greater than expected and had the highest rate per year of all the focus areas.

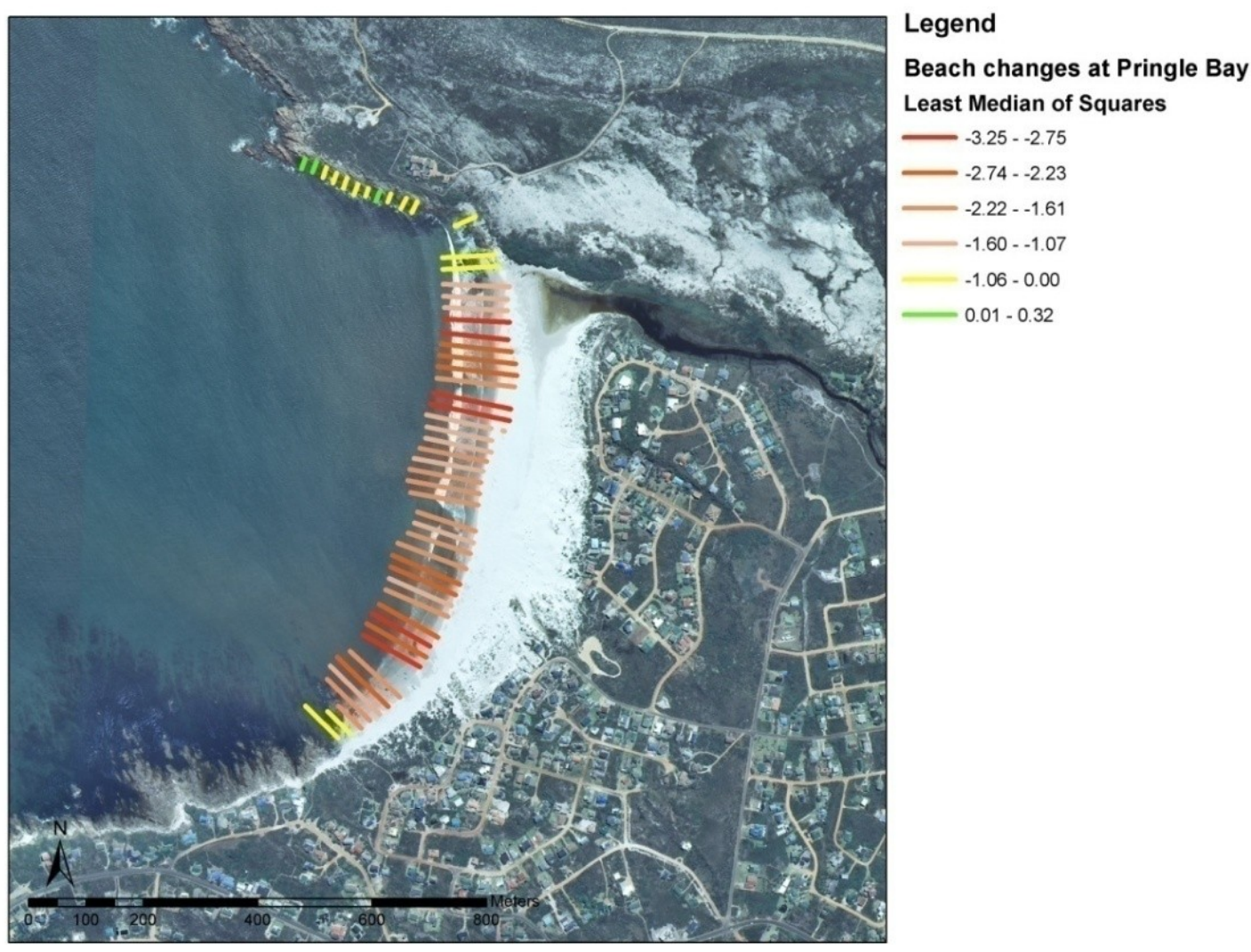

Figure 8. Least median of squares at Pringle Bay.

\section{Discussion and concluding remarks}

The results of this study have shown considerable changes in erosion susceptibility over the past 30 years throughout the study area. Increases in built-up regions, along with decreases in sand dune regions and a steady decrease in NDVI all indicate anthropogenic influences and decreases in vegetation health and density. The increased urbanisation increases the susceptibility to erosion by removing natural landcover and placing greater demand on the region through increased vehicle and pedestrian traffic in susceptible areas, as well as the increased pollution associated with a human settlement. In addition, it makes humans more vulnerable to the effects of erosion since structures near the coast are susceptible to damage by coastal erosion.

The NDVI differencing method showed consistent decreases in NDVI over time, which indicates decreases in vegetation health and density. This naturally results in an increase in susceptibility to erosion within the study area. The sand dune class specifically showed significantly decreased 
NDVI values over nearly the entire class area during the study period. This indicates an increased susceptibility to erosion of the sand dunes as well as their associated beaches.

Post-classification change detection at Bayview Heights showed changes from the ocean to the shallow coastal class in an increasing amount down towards the harbour. This provides evidence that the construction of the harbour has resulted in a build-up of ocean sediments. NDVI in this area shows both localised increases and decreases, which may be one reason why this region has shown a combination of accretion and erosion. The analysis of the aerial photographs showed that Bayview Heights exhibited the least change of the four focus areas. The presence of the harbour in this region does make it a more vulnerable region, but does not necessarily make it more susceptible to erosion. The DSAS rate-of-change statistics have indicated a fluctuation between erosion and accretion in this area. Erosion is seen mostly within the northern portion of this study region while the southern portion experiences accretion. The construction of the harbour at Bayview Heights prevents free movement of the sediments past this point and may have prevented higher erosional levels. This suggests that anthropogenic modifiers may affect the susceptibility to erosion in the region.

Post-classification change detection in the Macassar Beach area indicated a rapid increase in urbanised areas at the expense of the once extensive dune field. This has increased the susceptibility to erosion in this region. While the change of sand dune and other classes to built-up does not indicate erosion, it does indicate alteration to the natural system and an increased susceptibility to future erosion. This conclusion is supported by the decreases in NDVI across the dune field, although there are some localised increases in NDVI. DSAS results in this area showed a yearly average of erosion despite some artificial accretion which occurred due to the construction of the tidal pool, which again is indicative of anthropogenic influences. This is also a dynamic shoreline with fluctuations between accretion and erosion, however there is an overall trend towards erosion.

At Strand, post-classification change detection also showed areas where sand dune and other classes have changed to built-up. As with Macassar Beach, this is a sign of increased erosion susceptibility in this region. NDVI has shown only decreases in this focus area and so also indicates increased susceptibility to erosion. DSAS results at Strand show that there was no net accretion over the entire focus area - the whole area experienced net erosion. Although there was also fluctuation between erosion and accretion, there is only net erosion and this could have serious implications for structures on and near the beach in coming years.

Post-classification change detection at Pringle Bay showed few significant changes in this region. There was a change from shallow coastal to ocean which could be indicative of erosion. DSAS results here showed greater changes in beachfront position than expected. It is possible that the surrounding protruding rocky coast may have encouraged greater tidal range at this location. The region near Cape Hangklip and off Gordon's Bay does experience localised wind-induced upwelling (Harrison, 1998), which could have resulted in increased erosion. NDVI has not decreased as much in this area and has even shown some localised increases at the beach. It must 
therefore be other factors such as the localised upwelling which have resulted in erosion in this area. DSAS results in this area show erosion over the sandy beach area with some accretion at the rocky zone.

The findings of this study indicated that both high and medium resolution data could be used to extract information on erosion and erosion susceptibility in the region. The resolution of the Landsat imagery $(30 \mathrm{~m})$ was not sufficient to definitively detect changes in beach position and, consequently, could not quantify erosion or accretion rates or the net changes in shoreline positions over time. However, Landsat images were able to aid in detection of various changes in the surrounding areas which have a direct influence on the susceptibility to coastal erosion. This includes the identification of areas where a decrease in the health and productivity of vegetation and an increase in reflective surfaces (such as sand and built-up areas) may lead to an increase in erosion susceptibility. This information may be useful for the formulation of mitigation strategies in high susceptibility areas.

On the other hand, the high resolution aerial photographs with DSAS provided the advantage of greatly enhanced detail in the beach zone. The high resolution provided by the aerial photographs provided the opportunity to quantify erosion and accretion rates over time, as well as calculate the net shoreline change over extended periods. The disadvantage of this technique is that it relies on manual digitisation of shoreline features, which is time consuming and increases the reliance on human interpretation of shoreline positions over time. This means that potential ambiguities can be introduced based on user bias.

This study set out to employ different sensors and techniques for the detection of coastal erosion and erosion susceptibility in False Bay, South Africa. There is a global trend towards coastal degradation and a need to find the most effective methods for monitoring this. The results of this study have shown considerable changes in erosion susceptibility over the past 30 years. Anthropogenic influences were significant and there was a consistent increase in built-up areas with associated losses in vegetation. Consistent erosion of the beach was also seen in the focus areas.

High and medium resolution remote sensing data and image analysis tools provided a means to observe both general trends in erosion susceptibility, and specific changes in shoreline position over time. It is recommended that future studies make use of aerial photographs or high resolution satellite imagery when the aim is to view and quantify changes in the beach itself. An investigation of automated feature extraction techniques, such as edge detection or segmentation, for the extraction of shoreline indicators is recommended to decrease the possibility of introducing user bias. The lower resolution of Landsat imagery makes it more suited to assessment of long-term regional changes in erosion susceptibility and characterisation of large study areas. 


\section{References}

Althausen, JD, Kendall, CGSTC, Lakshmi, V, Alsharhan, AS, \& Whittle, GL 2003, 'Using satellite imagery and GIS in the mapping of coastal landscapes in an arid environment: Khor Al Bazam, Western Abu Dhabi, United Arab Emirates', in Alsharhan, AS, Wood, WW, Goudie, AS, Fowler, A, and Abdellatif, EM (eds.), Desertification in the Third Millennium, AA Balkema/Swets\&Zeitlinger, Rotterdam

Boak, EH, \& Turner, IL 2005, 'Shoreline definition and detection: a review', Journal of Coastal Research vol. 21, no. 4, pp. 688-703.

Boruff, BJ, Emrich, C \& Cutter, SL 2005, 'Erosion hazard vulnerability of US coastal counties', Journal of Coastal Research vol. 21, no. 5, pp. 932-942.

Drăgut,, L, Teide, D, \& Levick, SR 2010, 'ESP: a tool to estimate scale parameter for multiresolution image segmentation of remotely sensed data' International Journal of Geographical Information Science, vol. 24, no. 6, pp. 859-871.

Harrison, TD, 1998. 'A preliminary survey of the coastal river systems of False Bay, South-west coast of South Africa, with particular reference to the fish fauna.' Transactions of the Royal Society of South Africa, vol. 53, no. 1, pp. 1-31.

Hayes, DJ, \& Sader, SA 2001, 'Comparison of change-detection techniques for monitoring tropical forest clearing and vegetation regrowth in a time series' Photogrammetric Engineering and Remote Sensing, vol. 67 , no. 9, pp. 1067-1075.

Huang, W, \& Fu, B, 2002, 'Remote sensing for coastal area management in China' Coastal Management, vol. 30 , no. 3, pp. 271-276.

Kamagata, N, Hara, K, Mori, M, Akamatsu, Y, Li, Y, \& Hoshino, Y 2006, 'A new method of vegetation mapping by object-based classification using high resolution satellite data', In Proc. It $^{\text {st }}$ Int. Conf. ObjectBased Image Anal. 2006, vol. XXXVI-4, no. C42.

Kwarteng, AY \& Al-Ajmi, D 1996, 'Using Landsat Thematic Mapper data to detect and map vegetation changes in Kuwait', International Archives of Photogrammetry and Remote Sensing, vol. XXXI, part B7.

Lu, D, Mausel, P, Brondízio, E, \& Moran, E 2004, ,Change detection techniques', International Journal of Remote Sensing, vol. 25, no. 12, pp. 2365-2401.

Lyons, MB, Phinn, SR, \& Roelfsema, CM, 2012, 'Long term land cover and seagrass mapping using Landsat and object-based image analysis from 1972 to 2010 in the coastal environment of South East Queensland, Australia', ISPRS Journal of Photogrammetry and Remote Sensing, vol. 71, pp. 34-46.

Mouat, DA, Mahin, GG, \& Lancaster, J 1993, 'Remote sensing techniques in the analysis of change detection', Geocarto International, vol. 8, no. 2, pp. 39-50.

Palmer, BJ, Van der Elst, R, Mackay, F, Mather, AA, Smith, AM, Bundy, SC, Thackeray, Z, Leuci, R, \& Parak, O 2011, 'Preliminary coastal vulnerability assessment for KwaZulu-Natal, South Africa', Journal of Coastal Research, Special Issue 64, pp 1390-1395.

Phillips, MR 2008, 'Beach erosion and marine aggregate dredging: a question of evidence', The geographical journal, vol. 174, no. 4, pp. 332-343.

Ryherd, S, \& Woodcock, C 1996, 'Combining spectral and texture data in the segmentation of remotely sensed images', Photogrammetric Engineering and Remote Sensing, vol. 62, no. 2, pp. 181-194.

Singh, A 1989, 'Review article: digital change detection techniques using remotely sensed data', International Journal of Remote Sensing, vol. 10, no. 6, pp. 989-1003. 
Siripong, A 2010, 'Detect the coastline changes in Thailand by remote sensing', International Archives of the Photogrammetry, Remote Sensing and Spatial Information Science, vol. XXXVIII, part 8, pp. 992-996.

Smith, SE, \& Abdel-Kader, A 1988, 'Coastal erosion along the Egyptian Delta', Journal of Coastal Research, vol. 4, no. 2, pp. 245-255.

Sun, X, Zhang, J, \& Liu, Z 2004, 'An object-oriented classification method on high resolution satellite data', in Chinese academy of Surveying and Mapping Beijing (China). Accession number: ADA437344

Thampanya, U, Vermaat, JE, Sinsakul, S, \& Panapitukkul, N 2006, ,Coastal erosion and mangrove progradation of Southern Thailand', Estuarine, Coastal and Shelf Science, vol. 68, pp. 75-85.

Thieler, ER, Himmelstoss, EA, Zichichi, JL, \& Ergul, A, 2009, ,Digital Shoreline Analysis System (DSAS) version 4.0 - An ArcGIS extension for calculating shoreline change', U.S. Geological Survey Open-File Report 2008-1278. *current version 4.3

Tralli, DM, Blom, RG, Zlonicki, V, Donnellan, A, \& Evans, DL 2005, 'Satellite remote sensing of earthquake, volcano, flood, landslide and coastal inundation hazards', ISPRS Journal of Photogrammetry and Remote Sensing vol. 59, pp. 185-198.

Unterner, M, Wigley, R, van Zyl, W, Cawthra, H, \& Machutchon, M 2011, 'The vulnerability of the South African coastline to erosion', Council for Geoscience Report number 2011-0190.

Van der Werff, HMA, \& van der Meer, FD 2008, , Shape-based classification of spectrally identical objects', ISPRS Journal of Photogrammetry and Remote Sensing vol. 63, pp/ 251-258.

Van Niekerk, A 2012, 'Developing a very high resolution DEM of South Africa', PositionIT, Nov/Dec, pp. 55-60.

Woodcock, CE, Macomber, SA, Pax-Lenney, M, \& Cohen, WB 2001, 'Monitoring large areas for forest change using Landsat: Generalization across space, time and Landsat sensors', Remote Sensing of Environment, vol. 78, pp. 194-203.

Zhang, K, Douglas, BC, \& Leatherman, SP 2001, 'Beach erosion potential for severe nor'easters', Journal of Coastal Research, vol. 17, pp. 309-321.

Zhang, Q, Wang, J, Peng, X, Gong, P, \& Shi, P 2002, 'Urban built-up land change detection with road density and spectral information from multi-temporal Landsat TM data', International Journal of Remote Sensing, vol. 23, no. 15, pp. 3057-3078. 